\title{
LAS MEDIDAS DE REPARACIÓN INTEGRAL ESTABLECIDAS EN EL “ACUERDO FINAL PARA LA TERMINACIÓN DEL CONFLICTO Y LA CONSTRUCCIÓN DE UNA PAZ ESTABLE Y DURADERA”
}

\author{
INTEGRAL REPAIRING MEASURES ESTABLISHED IN THE \\ “AGREEMENT FOR THE TERMINATION OF THE CONFLICT AND THE \\ CONSTRUCTION OF A STABLE AND LASTING PEACE”
}

Hugo Andrés Arenas Mendoza

Universidad del Rosario (Bogotá, Colombia)

Recebimento: 20 fev. 2017

Aceitação: 15 ago. 2017

\begin{abstract}
Como citar este artigo / How to cite this article (informe a data atual de acesso / inform the current date of access):
MENDOZA, Hugo Andrés Arenas. Las medidas de reparación integral establecidas en el "Acuerdo Final para la Terminación del Conflicto y la Construcción de una Paz Estable y Duradera”. Revista da Faculdade de Direito UFPR, Curitiba, PR, Brasil, v. 62, n. 3, p. 9-29, set./dez. 2017. ISSN 2236-7284. Disponível em: $<$ http://revistas.ufpr.br/direito/article/view/50780>. Acesso em: 21 dez. $2017 . \quad$ DOI:
\end{abstract} http://dx.doi.org/10.5380/rfdufpr.v62i3.50780.

\section{RESUMEN}

El resultado del diálogo de paz iniciado en el año 2012, entre el Gobierno colombiano y la guerrilla de las FARC, fue el "Acuerdo final para la terminación del conflicto y la construcción de una paz estable y duradera"; este texto fue sometido a plebiscito el 2 de octubre de 2016, teniendo como consecuencia la no aprobación del acuerdo por parte del pueblo colombiano, concretamente con el $50.21 \%$ de la votación. Ante esto, el gobierno ha solicitado que sea aprobado por el Congreso mediante un procedimiento especial, sin embargo, todavía no hay una respuesta definitiva. Este artículo presenta el contenido general del acuerdo de paz suscrito entre la guerrilla de las FARC y el gobierno colombiano, concretamente en lo referente a la reparación integral a las víctimas, sus principios ordenadores, sus lineamientos generales y las medidas de reparación. El "Acuerdo para la terminación del conflicto y la construcción de una paz estable y duradera”, hace referencia en varias ocasiones a la noción de reparación integral, estableciéndola como una directriz para la indemnización a las víctimas. Así, se destaca que el mencionado texto hace una referencia muy general a las medidas de reparación individual al punto de sólo mencionarlas, sin explicar su contenido y al contrario, le da un gran protagonismo a las medidas de reparación colectiva, desarrollándolas ampliamente.

\section{PALABRAS CLAVE}

Reparación. Víctimas. Acuerdo. Colombia. FARC.

\section{ABSTRACT}

The outcome of the peace dialogue that started in 2012, between the Colombian government and the guerrilla of FARC, was the "Final agreement for the termination of the conflict and the construction of a stable and lasting peace"; this text was submitted to a plebiscite on October 2nd 2016, having the Colombian people not approving the Agreement as a consequence, particularly with a 50,21\% voting. 
Because of this, the government has requested for the Agreement to be passed by Congress by means of a special proceeding, nevertheless there still is no final decision. This article presents the general content of the peace treaty entered into by the guerilla of FARC and the Colombian government, in particular regarding the integral reparation of victims, their governing principles, their general guidelines and the repairing measures. The "Agreement for the termination of the conflict and the construction of a stable and lasting peace" makes reference in various occasions to the notion of integral repair, establishing it as a guideline for the repair of victims. It should be highlighted that the referenced text makes a very general reference to the individual repairing measures to the point of just mentioning them, not explaining their content and, on the contrary, giving an important role to the collective repairing measures, developing them broadly.

\section{KEYWORDS}

Repair. Victims. Agreement. Colombia. FARC.

\section{INTRODUCCIÓN}

El resultado del diálogo de paz iniciado en el año 2012, entre el Gobierno colombiano y la guerrilla de las FARC, fue el "Acuerdo final para la terminación del conflicto y la construcción de una paz estable y duradera”; este texto fue sometido a plebiscito el 2 de octubre de 2016 y el resultado fue la no aprobación del acuerdo por parte del pueblo colombiano, concretamente con el 50.21\% de la votación.

Uno de los puntos centrales del acuerdo es la reparación a las víctimas del conflicto armado colombiano, tema al que se hace referencia en varias partes del acuerdo incorporados principalmente en el punto 5, titulado: “Acuerdo sobre las víctimas del Conflicto: "Sistema integral de Verdad, Justicia, Reparación y No Repetición, incluyendo la Jurisdicción Especial para la Paz; y Compromiso sobre Derechos Humanos”, que se subdivide en: Una parte introductoria; 5.1. Sistema integral de Verdad, Justicia, Reparación y no Repetición; 5.2. Compromiso con la promoción, el respeto y la garantía de los derechos humanos y 5.3. Acuerdo complementario sobre el "Sistema Integral de Verdad, Justicia, Reparación y No repetición”.

En este sentido se debe destacar que las partes eligieron incluir en el texto del acuerdo la noción de reparación integral, como un criterio fundamental para la indemnización de las víctimas y para la materialización de las medidas tanto individuales como colectivas contenidas en el texto definitivo.

Este artículo destaca que el acuerdo hace una referencia muy general a las medidas de reparación individual al punto de sólo mencionarlas, sin explicar su contenido y al contrario, le da un gran protagonismo a las medidas de reparación colectiva, desarrollándolas ampliamente. De este modo, es aconsejable darle un mayor contenido a las reparaciones individuales para que realmente 
las víctimas tengan acceso a una verdadera reparación integral y que una vez sea garantizada esta, se piense en realizar reparaciones colectivas.

En este orden de ideas, el presente texto será dividido en los siguientes cuatro puntos que son: 1. Principios del Acuerdo, 2. Enfoques que se le pueden asignar a la responsabilidad patrimonial por los daños causados en el conflicto armado, 3. La reparación integral en el acuerdo y 4. Las medidas de reparación integral para la construcción de la paz.

\section{PRINCIPIOS DEL ACUERDO}

Como se explicó en la introducción de este libro, el “Acuerdo final para la terminación del conflicto y la construcción de una paz estable y duradera” está compuesto por un preámbulo, una introducción y seis puntos que son: 1. Hacia un nuevo Campo Colombiano: Reforma Rural Integral; 2. Participación Política: Apertura democrática para construir la paz; 3. Fin del conflicto; 4. Solución al problema de las drogas ilícitas; 5. Acuerdo sobre las víctimas del Conflicto: "Sistema integral de Verdad, Justicia, Reparación y No Repetición”, incluyendo la Jurisdicción Especial para la Paz; y Compromiso sobre Derechos Humanos y 6. Implementación, verificación y refrendación. Además, el texto presenta al final un acápite sobre protocolos y anexos.

En la parte introductoria del acuerdo se encuentra la "Declaración de principios” del 7 de junio de 2014, estableciendo los siguientes 10 principios: El reconocimiento de las víctimas, El reconocimiento de la responsabilidad, Satisfacción de los derechos de las víctimas, La participación de las víctimas, El esclarecimiento de la verdad, La reparación de las víctimas, Las garantías de protección y seguridad, La garantía de no repetición, Principio de reconciliación y 1.10. Enfoque de derechos $^{1}$. A continuación se analizará cada uno de estos principios lo cual resulta relevante para la línea argumentativa seguida en este texto:

- El reconocimiento de las víctimas: "Es necesario reconocer a todas las víctimas del conflicto, no solo en su condición de víctimas, sino también y principalmente, en su condición de ciudadanos con derechos”. Este principio consagra la centralidad de la víctima en el Acuerdo, lo que se traduce en hacer prevalecer los derechos de las personas afectadas por el conflicto por encima de intereses políticos o conveniencias de otros sujetos participantes en la guerra.

\footnotetext{
${ }^{1}$ Ver Acuerdo Final, 24 de noviembre de 2016, p. 124-125, disponible en: <https://goo.gl/VRHqXX>.
} 
- El reconocimiento de la responsabilidad: “Cualquier discusión de este punto debe partir del reconocimiento de responsabilidad frente a las víctimas del conflicto. No vamos a intercambiar impunidades”. La responsabilidad por los hechos cometidos durante el conflicto armado deberá ser asumida siempre, el proceso de paz no puede servir de instrumento para evitar que los victimarios puedan eludir sus compromisos por los daños causados a los damnificados.

- Satisfacción de los derechos de las víctimas: "Los derechos de las víctimas del conflicto no son negociables; se trata de ponernos de acuerdo acerca de cómo deberán ser satisfechos de la mejor manera en el marco del fin del conflicto”. Nuevamente, se destaca el enfoque sobre la protección de los derechos de la víctima, precisando que no son renunciables o negociables. Lo único que se busca es que sean respetados e indemnizados de la manera más favorable posible.

- La participación de las víctimas: “La discusión sobre la satisfacción de los derechos de las víctimas de graves violaciones de derechos humanos e infracciones al Derecho Internacional Humanitario con ocasión del conflicto, requiere necesariamente de la participación de las víctimas, por diferentes medios y en diferentes momentos”. Para lograr la verdadera garantía de la satisfacción de los derechos de las víctimas de violaciones de derechos humanos e infracciones al DIH se requiere una participación activa de las víctimas durante todo el procedimiento y no en un momento concreto. Con esto se busca conocer los hechos, para poder proceder a reparar a las personas de manera integral.

- El esclarecimiento de la verdad: "Esclarecer lo sucedido a lo largo del conflicto, incluyendo sus múltiples causas, orígenes y sus efectos, es parte fundamental de la satisfacción de los derechos de las víctimas, y de la sociedad en general. La reconstrucción de la confianza depende del esclarecimiento pleno y del reconocimiento de la verdad”. El derecho a conocer la verdad es una de las metas del proceso de paz, puesto que permite reconstruir la confianza entre los intervinientes y sobre todo, en el Estado colombiano. Así mismo, permite identificar las causas y efectos de la guerra, para poder conocer sus alcances, reparar la totalidad de los daños y evitar la ocurrencia de hechos similares.

- La reparación de las víctimas: "Las víctimas tienen derecho a ser resarcidas por los daños que sufrieron a causa del conflicto. Restablecer los derechos de las víctimas y transformar sus condiciones de vida en el marco del fin del conflicto es parte fundamental de la construcción de la paz estable y duradera”. La reparación de las víctimas debe ser integral, indemnizando tanto los daños materiales como los inmateriales que hayan padecido por la guerra. Del mismo modo, se debe buscar que los afectados vivan en condiciones de paz, que les garanticen la protección de sus derechos. 
- $\quad$ Las garantías de protección y seguridad: "Proteger la vida y la integridad personal de las víctimas es el primer paso para la satisfacción de sus demás derechos”. En este apartado, se destaca la necesidad de proteger la vida y la integridad de las personas, para que no queden en la situación de vulnerabilidad en que se encontraban durante la existencia del conflicto armado.

- La garantía de no repetición: "El fin del conflicto y la implementación de las reformas que surjan del Acuerdo Final, constituyen la principal garantía de no repetición y la forma de asegurar que no surjan nuevas generaciones de víctimas. Las medidas que se adopten tanto en el punto 5 como en los demás puntos de la Agenda deben apuntar a garantizar la no repetición de manera que ningún colombiano vuelva a ser puesto en condición de víctima o en riesgo de serlo”. Para que los colombianos podamos vivir en paz, es necesario que los daños que se produjeron a las personas durante la guerra no se repitan, que los hechos queden en la memoria colectiva para que nunca más se pongan a los ciudadanos en condición de víctima o en riesgo de serlo.

- Principio de reconciliación: "Uno de los objetivos de la satisfacción de los derechos de las víctimas es la reconciliación de toda la ciudadanía colombiana para transitar caminos de civilidad y convivencia”. Se debe tener presente que para que haya una verdadera reconciliación entre los intervinientes en el conflicto con sus víctimas, es necesario que se satisfagan todos los derechos de las víctimas y a partir de esto, se empiece a vivir en convivencia en Colombia.

- Enfoque de derechos: “Todos los acuerdos a los que lleguemos sobre los puntos de la Agenda y en particular sobre el punto 5 “Víctimas” deben contribuir a la protección y la garantía del goce efectivo de los derechos de todos y todas. Los derechos humanos son inherentes a todos los seres humanos por igual, lo que significa que les pertenecen por el hecho de serlo, y en consecuencia su reconocimiento no es una concesión, son universales, indivisibles e interdependientes y deben ser considerados en forma global y de manera justa y equitativa. En consecuencia, el Estado tiene el deber de promover y proteger todos los derechos y las libertades fundamentales, y todos los ciudadanos el deber de no violar los derechos humanos de sus conciudadanos. Atendiendo los principios de universalidad, igualdad y progresividad y para efectos de resarcimiento, se tendrán en cuenta las vulneraciones que en razón del conflicto hubieran tenido los derechos económicos, sociales y culturales”. Este principio reivindica la importancia de los derechos humanos, que tienen todas las personas y busca el compromiso tanto del Estado como de los particulares para que cesen las violaciones a los derechos humanos en nuestro país. 
Concretamente, en el tema de reparación patrimonial, los anteriores principios son importantes en la medida en que indican los parámetros generales que serán utilizados por los actores para lograr la reparación de las víctimas, incentivar el reconocimiento de los derechos humanos, evitar que se repitan estas situaciones, que exista el perdón entre los implicados, se conozca la verdad y para que los colombianos puedan vivir pacíficamente.

Finalmente, se debe tener presente que estos principios son de obligatorio cumplimiento, por lo que deben ser acatados tanto por el Estado como por los miembros de las FARC y que se aplican a todas las actuaciones e indemnizaciones que se realicen desde el momento de la firma del acuerdo.

\section{ENFOQUES QUE SE LE PUEDEN ASIGNAR A LA RESPONSABILIDAD PATRIMONIAL POR LOS DAÑOS CAUSADOS EN EL CONFLICTO ARMADO}

Una parte esencial del Acuerdo consistía en elegir el enfoque teórico que se sirva de fundamento para la reparación de los daños, evitar la ocurrencia de hechos similares y la manera en que se va a castigar a los infractores patrimonialmente. Con base en esto, se han desarrollado tesis basadas en cuestiones de justicia, económicas, de control social, sancionatorias, de reparación integral, etcétera.

El “Acuerdo para la terminación del conflicto y la construcción de una paz estable y duradera”, hace referencia en varias ocasiones a la noción de reparación integral, estableciéndola como una directriz para la indemnización a las víctimas.

Antes de concentrarse en el acuerdo, es preciso presentar los diversos enfoques que se le pueden asignar a la responsabilidad por los daños cometidos, puesto que de esto dependerá la manera en que se indemnice a las víctimas del conflicto armado, se castigue a los infractores y se eviten la ocurrencia de hechos similares. En este orden de ideas, se debe hacer referencia a las funciones: Punitiva, Preventiva, Control Social, Económica, Solidaridad, Reparadora, Transformadora y Reparación integral:

- Punitiva: Esta visión proviene del derecho norteamericano, tomando una visión proveniente del derecho penal que permite que la lesión sea indemnizada por encima del detrimento 
sufrido $^{2}$. Se basa en la reparación como castigo ${ }^{3}$ y tiene la finalidad de que se disuada a las personas de repetir el comportamiento ${ }^{4}$.

- Preventiva: Pretende influenciar en el comportamiento de los agentes que pueden generar la responsabilidad, con el fin de evitar la ocurrencia de otros daños ${ }^{5}$. En consecuencia, su función primordial es impedir que se cometan nuevos daños, al cambiar la motivación de los agentes ${ }^{6}$, por medio de que conozca el impacto de su conducta; por ejemplo, que sea demasiado oneroso, sus fuertes sanciones o traigan un deterioro medioambiental.

- Control social: El Estado tiene que realizar unas funciones que le han sido atribuidas constitucionalmente, para materializarlas debe realizar actuaciones u omisiones, que pueden causar daños a los asociados. Por esto, alguna parte de la doctrina ha entendido que la responsabilidad tiene una función de control social, es decir, sirve como mecanismo para evaluar el comportamiento de las instituciones ${ }^{7}$ y también una función marcadamente pedagógica ${ }^{8}$.

- $\quad$ Económica: La visión económica del derecho de daños, iniciada por Guido Calabresi9 ${ }^{9}$, considera que las personas son racionales en sus decisiones, calculando los costos de sus actuaciones y por esto, si el daño causado es mayor que el beneficio obtenido, las personas lo evitarán. Como lo explica Coleman: “Esta característica podría resumirse en que la responsabilidad extracontractual

\footnotetext{
2 "Esta regla de oro del derecho de daños no opera, sin embargo, en países de corte anglosajón, en los cuales el concepto de 'daño punitivo' - punitive, exemplary, punitory, vindicative damages- permite sobrepasar sin problema la regla en estudio en favor de la víctima”. Henao, Juan, El daño. Análisis comparativo de la responsabilidad extracontractual del Estadoen el derecho colombiano y en el francés, Universidad Externado de Colombia, Bogotá, 2007, p. 45.

3 "La idea central era la reparación como castigo, ya que si a todos los hombres en la sociedad se los presentaba formalmente como libres e iguales, el daño aparecía como un conducta desviada que debía ser reencausada por medio de la sanción del agente dañador, y muy especialmente haciendo hincapié en el aspecto patrimonialista de la problemática”. Ghersi, Carlos, Teoría de la reparación de daños, Editorial Astrea, Buenos Aires, 2013, p. 32.

4 “A la responsabilidad se le atribuía una función disuasiva: era concebida como la sanción impuesta para quien, trasgrediendo el precepto del neminem laedere, hubiese causado perjuicio al derecho de otros”. Galgano, Francesco, I fatti illecitti, Casa Edirtice Dott. Abtonio Millani, Padova, 2008, p. 15.

5 “Las reglas de la responsabilidad civil pueden así cumplir una benéfica función preventiva. Adecuadamente configurada, pueden inducir a todos los sujetos implicados a tomar medidas eficientes de precaución contra el riesgo de que ciertos bienes jurídicos resulten lesionados”. Doménech, Gabirel, “El principio de responsabilidad patrimonial de los poderes públicos, en Los principios jurídicos del derecho administrativo, Editorial la Ley, madrid, 2010, p. 667.

6 "El correcto y completo despliegue de esta función preventiva exige que la responsabilidad civil (y el estímulo que representa) alcance no sólo a la Administración, como organización, sino también a las concretas personas físicas que la integran y actúan a su servicio”. Mir, Oriol, La responsabilidad de la Adminsitración: Hacia un nuevo sistema, Civitas ediciones, Madrid, 2002, p. 145.

7 "La institución de la responsabilidad civil de la Administración puede y debe servir para controlar el buen funcionamiento de los servicios públicos. Ésta es una función que no se debe malograr y que conviene potencializar.” Mir, Oriol, op. cit., p. 147-148.

8 "Esa función pedagógica supone que la Administración aprenda a cómo debe actuar en el futuro para evitar ser condenada”. Rebollo, Luis, Responsabilidad patrimonial de las entidades locales, Editorial Iustel, Madrid, 2005, p. 221.

9 "Guido Calabresi fue el primer autor en hacer en hacer un estudio sistemático, aunque sin valerse de modelos formales, de los objetivos económicos del derecho de daños”. Papayannis, Diego, Comprensión y justificación de la responsabilidad extracontractual, Marcial Pons, Madrid, 2014, p. 39.
} 
articula un marco de permisos y precios, de juicios sobre lo que pueden hacer los individuos y los precios que deben pagar para hacerlo” (COLEMAN, 2010, p. 92).

- Solidaridad: La solidaridad que se predica inherente a los Estados Sociales de Derecho, es otra función que se le ha atribuido a la responsabilidad estatal ${ }^{10}$. La tesis de la redistribución de riqueza ha sido fuertemente criticada por la doctrina, al entender que la naturaleza de la responsabilidad es muy diversa a la de otras figuras como los fondos, las subvenciones u otros tipos de medidas asistenciales desarrolladas por el Estado ${ }^{11}$.

- $\quad$ Reparadora: La función reparadora o de garantía se basa en la justicia correctiva y busca la reparación de los daños causados por el Estado a los particulares ${ }^{12}$. Al sufrir un daño a su patrimonio, por afectación a sus bienes materiales o inmateriales, lo que se busca es que la persona no vea disminuida las condiciones en las que se encontraba antes de la ocurrencia del hecho. Así, como lo expresa Juan Henao: "El daño es la causa de la reparación y la reparación es la finalidad última de la responsabilidad civil” (HENAO, 2007, p. 37).

- La transformadora: Una reciente propuesta creada para ser utilizada en situaciones postconflicto o donde se han producido violaciones a Derechos Humanos es la función transformadora $^{13}$. La justicia transformadora que se aplica en casos puntuales de sociedades desiguales, busca armonizar las nociones clásicas de justicia correctiva y distributiva y se materializa en programas de reparación ${ }^{14}$.

\footnotetext{
10 "De allí que la solidaridad no puede ser entendida única y exclusivamente como expresión de la justicia distributiva aristotélica, sino que, por el contrario, puede llegar a expresar -desde el plano de la responsabilidad- un sustento filosófico y jurídico para determinar cuándo alguien está compelido a indemnizar el perjuicio causado”. Gil, Enrique, La constitucionalización del derecho de daños, Editorial Temis, Bogotá, 2014, p. 21.

11 "El derecho de la responsabilidad patrimonial es ajeno por completo a cualquier finalidad asistencial, sin que los mecanismos jurídicos de la beneficencia tengan nada que ver con él. La responsabilidad patrimonial no es obra jurídica de misericordia; y cualesquiera medidas de signo asistencial que compensen los daños sufridos (al margen del responsable) rebasan sus límites intrínsecos, insertándose en el seno de un Estado Social, como reacción tuitiva frente a la insalvable insuficiencia de su regulación”. Medina, Luis, "La responsabilidad patrimonial de las Adminsitraciones Públicas”, en Lecciones y materiales para el estudio del derecho administrativo, Iustel, Madrid, 2009, p. 54.

12 "No cabe en efecto, concebir una responsabilidad administrativa que no tenga como objetivo prioritario que la compensación de daños, la indemnización a las víctimas”. Mir, Oriol, La responsabilidad de la Adminsitración: Hacia un nuevo sistema, Civitas ediciones, Madrid, 2002, p. 144.

13 "Así pues, de cara a las violaciones masivas y protuberantes de los derechos en Colombia, exponen la necesidad de apreciar la reparación no solo como una forma de justicia correctiva, sino como un modo de impulsar transformaciones democráticas en la sociedad”. Henao, Juan, "Las formas de reparación en la responsabilidad del Estado: hacia su unificación sustancial en todas las acciones contra el Estado”, en La responsabilidad extracontractual del Estado, Universidad Externado de Colombia, Bogotá, 2015, p. 110.

14 "Por ello, hemos desarrollado el concepto de 'reparaciones transformadoras', o reparaciones dirigidas a promover la transformación democrática, como un esfuerzo por articular la justicia correctiva y la justicia distributiva en el diseño e implementación de los programas de reparación”. Uprimny, Rodrigo y Guzman, Diana, "En la búsqueda de un concepto transformador y participativo para las repraraciones en contextos transicionales”, en Revista colombiana de derecho intenacional, Número 17, Bogotá, 2010, p. 252.
} 
- Reparación integral: El desarrollo de las ideas sobre reparación integral surgió de la necesidad de perfilar mejor la función reparadora de la responsabilidad estatal. Con esto, los operadores jurídicos, pretenden hacer aplicable en la práctica una reparación que realmente pueda indemnizar todos los aspectos del patrimonio de la víctima, es decir, tanto los daños materiales como los inmateriales que haya sufrido.

\section{LA REPARACIÓN INTEGRAL EN EL ACUERDO}

En el Acuerdo final se hace recurrente referencia a la noción de reparación integral, que como se observó es tan solo una posibilidad entre otras para determinar las condiciones en que se realizará la reparación de los daños. Como se verá a continuación, la noción de reparación integral desarrollada en el acuerdo, ha sido acogida mayoritariamente por la doctrina, la legislación y la jurisprudencia nacional.

La reparación integral surgió de la necesidad de perfilar mejor la función reparadora, buscando que se logre un resarcimiento que realmente deje a la víctima en las condiciones en que se hallaba antes de producirse el perjuicio. Siguiendo a García de Enterría y a Tomás Ramón Fernández (2015, p. 419-420):

El principio general era (y es), por lo demás muy claro: la indemnización debe dejar $<<$ indemne $>>$ a la víctima del daño injusto, debe procurar una reparación integral del detrimento que dicho daño ha supuesto para su patrimonio, debe restituir este en su pleno valor anterior al suceso dañoso, debe cubrir; por tanto, todos los $<<$ daños y perjuicios $>>$ sufridos, $<<$ en cualquiera de sus bienes o derechos $>>$ [...].

Aunque, es evidente la gran acogida que tiene la noción de reparación integral en el derecho colombiano, es pertinente advertir, que hay parte de la doctrina que considera que no se deberían seguir sus parámetros, sino los establecidos por la reparación transformadora, por tratarse de un caso tan complejo como el del conflicto interno del país.

Con base en lo anterior, es necesario desarrollar tres puntos fundamentales sobre el tema de la reparación integral que son: 3.1 La reparación integral en la doctrina administrativista, 3.2 Sus principales críticas desde el punto de vista de la doctrina de la reparación transformadora y 3.3 La consagración de la reparación integral en el ordenamiento jurídico. 


\subsection{LA REPARACIÓN INTEGRAL EN LA DOCTRINA ADMINISTRATIVISTA COLOMBIANA}

La doctrina colombiana ha reconocido la vigencia del principio de reparación integral, entre otros, se destacan: Javier Tamayo (2011, p. 543), Libardo Rodríguez (2015, p. 656), Juan Henao (2007, p. 45), Ramiro Saavedra (2003, p. 605), Enrique Gil (2014, p. 47), Alán Brewer-Carías y Jaime Orlando Santofimio (2013, p. 239) y Hugo Arenas (2013, p. 145).

Según la doctrina más autorizada para una verdadera reparación integral, es necesario indemnizar tanto los daños materiales ${ }^{15}$ como los inmateriales ${ }^{16}$ causados a la víctima dentro del conflicto armado. Así mismo, para que se produzca una efectiva reparación es necesario que se actualice el valor de la condena al momento de ser pagada al afectado o de lo contrario, se producirán sanciones meramente simbólicas, que no permitan resarcir adecuadamente el daño percibido ${ }^{17}$.

En todo caso, es recomendable hacer uso de una noción más profunda de reparación como la proporcionada por Alán Brewer-Carías y Jaime Orlando Santofimio (2013, p. 239), quien le otorgan un carácter jurídico, político y sociológico, sustentando que:

En este sentido es mucho y materialmente más que un simple concepto indemnizatorio, al involucrar ideas de reconstrucción y reivindicación del ser humano en la sociedad. Luego el concepto de reparación conlleva cargas de individualismo pero también de responsabilidad colectiva. Desde una perspectiva estrictamente jurídica, es un derecho de toda víctima, sustentado en las ideas de verdad y justicia.

En la reparación integral el agente central es la víctima, es en torno a ella donde debe orientarse las actuaciones realizadas por las partes. Para esto, es necesario entender que el patrimonio de las personas incluye bienes materiales e inmateriales y por esto, la reparación integral no debe ser sólo económica, sino que implica entender la situación particular del individuo abordando, por ejemplo, cuestiones sicológicas, físicas, sociológicas y simbólicas.

\footnotetext{
15 "En cuanto a la cobertura de los daños baste señalar que la indemnización debe cubrir el daño emergente y el lucro cesante, en orden a procurar una reparación integral del daño”. De Ahumada, Francisco, La responsabilidad patrimonial de las Administraciones Públicas, Aranzadi, Pamplona, 2009, p. 197.

16 “Con base al principio de la integra reparación del daño, de hecho, no debe ser ignorado el aspecto no patrimonial de las lesiones ocasionadas por la administración. No tendría ningún sentido limitar tan sólo al daño patrimonial la protección ofrecida al privado”. Liberati, Alessio, La responsabilità della pubblica ammninistrazione ed il risarcimento del danno, Cedam, Padova, 2009, p. 180.

17 "El principio de reparación integral exige que se valore el daño atendiendo a la fecha en que se produjo (surgiendo, en consecuencia, la obligación resarcitoria), pero actualizando la cantidad a la fecha de la sentencia”. Medina, Luis, "La responsabilidad patrimonial de las Adminsitraciones Públicas”, en Lecciones y materiales para el estudio del derecho administrativo, Iustel, Madrid, 2009, p. 78.
} 


\title{
3.2 SUS PRINCIPALES CRÍTICAS DESDE EL PUNTO DE VISTA DE LA DOCTRINA DE LA REPARACIÓN TRANSFORMADORA
}

Aunque la función de la reparación integral es la que mayor acogida tiene en la actualidad, no quiere decir que exista unanimidad en el derecho nacional, sino que ha sido objeto de fuertes críticas. En este momento, se hará referencia a las cuatro principales objeciones formuladas por sus principales detractores, quienes consideran que para el caso del conflicto armado colombiano sería mucho más viable recurrir a una reparación trasformadora:

- La imposibilidad de retornar a la situación inicial: El principio de reparación resulta inaplicable en ciertas ocasiones en que es imposible regresar a la situación original: "En general, frente a las violaciones más graves de los derechos humanos, como una ejecución extrajudicial o una desaparición forzosa, el principio de restitutio in integrum resulta inaplicable pues no es posible retornar a la víctima a la situación en la cual se encontraba antes de que ocurriera la atrocidad” (UPRIMNY; GUZMAN, 2010, p. 240).

- La reparación integral solo aplica para perjuicios materiales: En los casos de perjuicios inmateriales no es real hablar de la aplicación de una verdadera reparación integral, quedando de lado el daño moral, daño corporal y las afectaciones a los bienes constitucional o convencionalmente protegidos. En palabras de Milagros Koteich (2012, p. 326-327):

\begin{abstract}
Por el contrario, cuando se trata de los perjuicios no económicos o de carácter personal, tal afirmación puede resultar poco 'realista' [...], pues, por carecer de precio el bien o interés lesionado, no es posible, si se nos permite la expresión, ir a la plaza o mercado -con la cantidad concedida- a 'readquirir' la integridad psicofísica vulnerada en forma permanente a la dignidad ofendida; como sí lo es en cambio cuando se trata de la lesión a un bien de carácter económico, por lo que puede sostenerse que cuando se trata del perjuicio extrapatrimonial o personal, no es posible, sin incurrir en un artificio, hablar de verdadera 'reparación integral $[\ldots]$.
\end{abstract}

- La reparación integral no funciona para situaciones como el conflicto armado

interno colombiano: La reparación integral está pensada para situaciones de normalidad en que, por regla general, no se violan derechos humanos: “Así, el principio la reparación integral genera paradojas y dilemas difíciles en sociedades que intentan saldar cuentas frente a violaciones graves y masivas a los derechos humanos, ocurridas en regímenes autoritarios o durante conflictos armados” (UPRIMNY; GUZMAN, 2010, p. 235).

- La reparación integral no está pensada para situaciones de responsabilidad colectiva: A las anteriores tres críticas, se debe agregar que no es la misma aproximación jurídica que se debe aplicar en el caso de que se trate de pocas víctimas o cuando se trate de colectividades. 
La reparación trasformadora lograría un mejor resultado de la utilización de los recursos públicos al realizar un programa conjunto que favorezca al conjunto de afectados y no tratar de indemnizar mínimamente a cada uno de los afectados.

\subsection{LA CONSAGRACIÓN DE LA REPARACIÓN INTEGRAL EN EL ORDENAMIENTO JURÍDICO COLOMBIANO}

En Colombia a partir de la Ley 446 de 1998, se estableció normativamente la reparación integral del daño explicando que: “Art. 16. "Dentro de cualquier proceso que se surta ante la Administración de Justicia, la valoración de los daños irrogados a las personas y a las cosas, atenderá los principios de reparación integral y equidad y observará los criterios técnicos actuariales”.

En ocasiones, se ha pretendido desdibujar el contenido de la reparación integral, diciendo que lo que pretendía el legislador era utilizar o una reparación integral y en otras una reparación en equidad. Afortunadamente, se ha aclarado que la reparación integral se debe llevar a su máxima expresión sin tener en consideración cuestiones presupuestales para bajar los montos de la condena a las víctimas.

Posteriormente, la reparación integral se ha mantenido en las leyes 975 de 2005, 1448 de 2011 y 1592 de 2012, las cuales están encaminadas a situaciones relativas a los daños producidos en el marco del conflicto armado interno colombiano. Esta normatividad incluyó las nuevas formas de reparación integral, que superan las tradicionales formas de indemnización dineraria o por especie.

Se debe tener presente que la jurisprudencia colombiana ha consagrado la noción de reparación integral, tanto la Corte Constitucional (ver Sentencias C-228/02, C-370/06, C-575/06, C1199/08, C-029/09 y C-286/14), como el Consejo de Estado (Por ejemplo, en las Sentencias de Unificación del 28 de agosto de 2014. Exps. 28804, 31172, 36149, 27709, 26251, 28832, 32988 y 31170). Se puede apreciar que se “[...] ha ampliado sustancialmente la reparación por fuera de aquella monetaria, es otra muestra del esfuerzo del juez en una interpretación más favorable a los administrados sustentada en normas constitucionales y en general en el bloque de constitucionalidad” (HENAO, 2014, p. 197). 


\subsection{LA REPARACIÓN INTEGRAL EN EL “ACUERDO FINAL PARA LA TERMINACIÓN DEL CONFLICTO Y LA CONSTRUCCIÓN DE UNA PAZ ESTABLE Y DURADERA”}

El acuerdo final hace referencia en más de diez ocasiones a la noción de reparación integral, estableciendo como un criterio orientador fundamental para la defensa de los derechos de las víctimas. En el tema concreto, de las medidas de reparación integral para la construcción de la paz establece:

Medidas de reparación integral para la construcción de la paz: Se trata de medidas que buscan asegurar la reparación integral de las víctimas, incluyendo los derechos a la restitución, la indemnización, la rehabilitación, la satisfacción y la no repetición; y la reparación colectiva de los territorios, las poblaciones y los colectivos más afectados por el conflicto y más vulnerables, en el marco de la implementación de los demás acuerdos. Con este fin, se fortalecerán los mecanismos existentes, se adoptarán nuevas medidas, y se promoverá el compromiso de todos con la reparación del daño causado ${ }^{18}$.

De la lectura del anterior párrafo se deriva que se utilizarán medidas de reparación integral tanto individuales como colectivas. Por una parte, las medidas individuales son las de restitución, indemnización, rehabilitación, satisfacción y no repetición y por la otra, las medidas de reparación colectivas.

Se debe tener presente que de la lectura conjunta del acuerdo se desprende que los daños serán reparados integralmente, en primera medida por sus causantes y el Estado concurrirá subsidiariamente a la reparación cuando los causantes no tengan dinero para pagarlos.

\section{LAS MEDIDAS DE REPARACIÓN INTEGRAL PARA LA CONSTRUCCIÓN DE LA PAZ}

La reparación integral busca que la víctima sea resarcida en cada uno de los ámbitos en que fue lesionado, por esto se deben indemnizar los daños sicológicos, los físicos y los económicos. En el derecho se permite la compensación de diferentes clases o tipologías de daños las cuales varían dependiendo del lugar y del momento al que se haga referencia.

En la actualidad en Colombia se reconoce la satisfacción tanto de los daños materiales como lo inmateriales. Los primeros se clasifican en daño emergente y lucro cesantes; mientras que, los segundos, se subdividen en daño moral, daño a la salud y la vulneración a bienes constitucional o convencionalmente protegidos (ARENAS, 2015, p. 263-275).

Siguiendo los lineamientos del derecho internacional público, que han sido aplicados por las Cortes colombianas en sus sentencias ${ }^{19}$, el texto del acuerdo nombra las medidas alternativas

\footnotetext{
${ }^{18}$ Ver Acuerdo Final, 24 de noviembre de 2016, p. 129-130, disponible en: <https://goo.gl/VRHqXX>.

${ }^{19}$ Sobre el tema ver: Brewer-Carías, Alán y Santofimio, Jaime, Control de convencionalidad y responsabilidad del Estado, Universidad Externado de Colombia, Bogotá, 2013, p. 316-347.
} 
individuales establecidas de reparación integral para la construcción de la paz, que buscan que se reparen tanto los daños materiales como los inmateriales que ha padecido la víctima.

\subsection{LAS MEDIDAS INDIVIDUALES DE REPARACIÓN INTEGRAL PARA LA CONSTRUCCIÓN DE LA PAZ INCORPORADAS EN EL ACUERDO}

Las medidas individuales de reparación integral son mecanismos encaminados a satisfacer a la víctima de una manera particular, se busca que el individuo sea resarcido en cada uno de los daños sufridos, bien sean sicológicos, físicos, económicos o a su dignidad. El acuerdo hace referencia, aunque solo las menciona, a las siguientes medidas individuales de reparación integral: Restituir, Indemnizar, Rehabilitar; Satisfacer y No repetir. Adicionalmente, debido al énfasis especial que se hace sobre el tema en el acuerdo, se debe hacer mención puntual a la Recuperación emocional.

- $\quad$ Restituir: La restitución se puede definir como las actuaciones enfocadas a regresar a la víctima a la situación anterior a la comisión de los hechos. Por ejemplo, que se le permita retornar al lugar del que fue desplazado o devolverle sus bienes tanto materiales como inmateriales.

- Indemnizar: La indemnización se puede entender como la compensación monetaria de un perjuicio, que debe corresponder con el monto del detrimento patrimonial sufrido; por esto, es necesario que se indemnice tanto el daño material como el inmaterial y se debe actualizar la suma al presente.

- Rehabilitar: Por rehabilitación se puede entender el conjunto de actuaciones realizadas hacia el bienestar de la víctima, tratando de recuperarla de las lesiones tanto sicológicas o físicas que haya padecido. Algunos ejemplos de medidas de rehabilitación serian la terapia física parar lograr la movilidad de alguna parte del cuerpo que haya sido afectada o la sicológica, para lograr superar algún recuerdo o sentimiento causado por el conflicto armado.

- $\quad$ Satisfacer: Para lograr la satisfacción de la víctima se pueden utilizar otras medidas simbólicas, con las que se busca lograr reparar algunos daños que pueden afectar otros derechos como la dignidad o el buen nombre de las personas. En este sentido, se puede ordenar entre otras posibilidades que se erija un monumento, se reconozca que actuaron inadecuadamente o se presenten disculpas públicas a los afectados.

- Garantías de no repetición: Las garantías de no repetición buscan que las personas que hayan sufrido un daño, no lo vuelvan a padecer. Para esto, se debe establecer las causas que originaron el daño y asegurar especial protección a las víctimas, para que no vayan a quedar de nuevo 
en situaciones de vulnerabilidad. Este tema es desarrollado con mayor profundidad en el punto 5.1.4. del acuerdo.

- Recuperación emocional: El acuerdo desarrolla textualmente las medidas de recuperación emocional a nivel individual, estableciendo:

En el marco del fin del conflicto, y con el fin de atender y contribuir a aliviar el sufrimiento de las víctimas, el Gobierno Nacional y las FARC-EP hemos acordado que el Gobierno Nacional, en desarrollo de este Acuerdo, se compromete a ampliar la cobertura pública y despliegue territorial, y mejorar la calidad de la atención psico-social para la recuperación emocional de las víctimas de acuerdo al daño específico que hayan padecido, entre ellas las afectaciones particulares de las víctimas de violencia sexual. Para ello se multiplicarán los centros locales de atención a las víctimas y se impulsarán estrategias móviles para llegar a los lugares más apartados.

Así mismo, en cumplimiento de los acuerdos alcanzados el Gobierno Nacional fortalecerá el acceso y los servicios de salud mental para las víctimas que así lo requieran.

Este apartado desarrolla tanto medias de reparación colectivas como individuales, pero no queda duda que la recuperación emocional a nivel individual y el mejoramiento en la cobertura de los servicios de salud mental para las víctimas que lo requieren contribuirán a facilitar la reparación integral de los afectados.

\subsection{LAS MEDIDAS COLECTIVAS DE REPARACIÓN INTEGRAL PARA LA CONSTRUCCIÓN DE LA PAZ ESTABLECIDAS EN EL ACUERDO}

Al lado de las medidas de reparación integral individual, el "Acuerdo final para la terminación del conflicto y la construcción de una paz estable y duradera”, incorpora las medidas de reparación integral colectivas.

Las reparaciones colectivas buscan tutelar los derechos de varias víctimas que hayan sufrido daños similares, como consecuencia de unos hechos parecidos; también, se puede tratar de colectivos o grupos de personas que han sufrido de daños $\operatorname{conjuntos}^{20}$. En todo caso, deben quedar completamente reparadas todas las lesiones padecidas, tanto los perjuicios materiales como los inmateriales.

Las medidas colectivas son desarrolladas en el punto "Reparación: Medidas de reparación integral para la construcción de paz”, donde se explica cada uno de los diversos mecanismos, a

\footnotetext{
20 "Es decir, se refiere al caso de que haya una multiplicidad de sujetos afectados individualmente, todos ellos identificados o identificables, caso en el cual por vía doctrinal se sostiene que estamos ante un daño masivo o grupal, que no es más que una manera de identificar la multiplicidad de daños individuales”. Santofimio, Orlando, “La cláusula constitucional de la responsabilidad del Estado: Estructura, régimen y el principio de convencionalidad como pilar de su construcción dogmática”, en Estudios sobre el control de convencionalidad, Colección de Estudios Jurídicos No. 109, Editorial venezolana, Caracas, 2015, p. 370.
} 
diferencia de las individuales a las que simplemente menciona. De este modo, hace referencia a: Actos tempranos de reconocimiento de responsabilidad colectiva, Acciones concretas de contribución a la reparación, La reparación colectiva en el fin del conflicto, Rehabilitación psico-social, Procesos colectivos de retornos de personas en situación de desplazamiento y reparación de víctimas en el exterior, Medidas sobre restitución de tierras y Adecuación y fortalecimiento participativo de la Política de atención y reparación integral a víctimas en el marco del fin del conflicto y contribución a la reparación material de las víctimas.

- Actos tempranos de reconocimiento de responsabilidad colectiva: Se trata de actos por parte de los responsables de los daños causados durante el conflicto para que reconozcan su responsabilidad colectiva y pidan perdón a las víctimas. Estos actos deberán ser formales, públicos y solemnes y se llevarán a cabo tanto en el ámbito nacional como en el territorial ${ }^{21}$.

- Acciones concretas de contribución a la reparación: Es la posibilidad que tienen las partes que causaron los daños, para que puedan realizar acciones concretas de reparación a las víctimas. El gobierno nacional se compromete a tomar medidas para garantizar la participación en las distintas medidas de reparación y las FARC se obligan, por ejemplo, a reincorporarse a la vida civil y a realizar acciones para reparar los daños causados (reparación de infraestructura, recolección de minas antipersonales, destrucción de municiones, sustitución de cultivos, ubicación de restos de personas, búsquedas de desaparecidos y reparación del daño ambiental) ${ }^{22}$.

- La reparación colectiva en el fin del conflicto: Con ellos se busca fortalecer los procesos de reparación colectiva, manteniendo el enfoque reparador en sus planes y programas de la reforma rural integral. El acuerdo diferencia entre estos tres lineamientos: a) Carácter reparador de los Planes de Desarrollo Rural con enfoque territorial, b) Planes de reparación colectiva con enfoque territorial y c) Planes nacionales de reparación colectiva ${ }^{23}$.

- Rehabilitación psico-social: Un importante punto en el acuerdo es la reparación de las víctimas en cada uno de los daños sufridos y por ende, se le da un tratamiento especial al tema de los efectos que pueden producir los hechos ocurridos en la mente de las personas. El acuerdo subdivide en medidas de recuperación a nivel individual (tema que se trató en el apartado anterior) y el plan de rehabilitación psico-social para la convivencia y no repetición, con el que se busca aumentar

\footnotetext{
${ }^{21}$ Ver Acuerdo Final, 24 de noviembre de 2016, p. 178, disponible en: <https://goo.gl/VRHqXX>.

${ }^{22}$ Ver Acuerdo Final, 24 de noviembre de 2016, p. 178-179, disponible en: <https://goo.gl/VRHqXX>.

${ }^{23}$ Ver Acuerdo Final, 24 de noviembre de 2016, p. 179-181, disponible en: <https://goo.gl/VRHqXX>.
} 
la rehabilitación comunitaria, para la reconstrucción del tejido social y en general, la recuperación de la confianza, la convivencia y la paz ${ }^{24}$.

- Procesos colectivos de retornos de personas en situación de desplazamiento y reparación de víctimas en el exterior: Son unos programas colectivos específicos de retorno y reubicación de víctimas, tanto para desplazados internos como para la que se encuentren en el exterior, que buscan la seguridad, la dignidad y la voluntariedad. Estos procesos colectivos deben tener en cuenta los elementos de identificación de territorios, la coordinación interinstitucional, la seguridad en los territorios para el retorno y el fortalecimiento de los defensores comunitarios ${ }^{25}$.

- Medidas sobre restitución de tierras: Son mecanismos tendientes a fortalecer y dinamizar los procesos de restitución de tierras. Entre sus lineamientos se destacan la utilización de expertos, de criterios técnicos, la construcción de infraestructura, el acceso a los servicios públicos, programas de reconstrucción de sus vidas, de generación de ingresos, sustitución de cultivos ilícitos, reconstrucción del tejido social y la construcción de memoria para la reconciliación ${ }^{26}$.

- Adecuación y fortalecimiento participativo de la Política de atención y reparación integral a víctimas en el marco del fin del conflicto y contribución a la reparación material de las víctimas: Las partes del acuerdo consideran la necesidad de fortalecer la Política de atención y reparación integral a la víctimas, logrando la mayor cobertura posible, para esto es necesaria la participación de las víctimas, organizaciones de víctimas, expertos académicos, entidades internacionales, organizaciones especializadas y defensores de derechos humanos. A partir de estas opiniones, el gobierno debe adecuar sus políticas, su ordenamiento jurídico y en general, facilitar los mecanismos necesarios para su ejecución ${ }^{27}$.

\section{CONCLUSIONES}

Existen varios enfoques o funciones que se le pueden atribuir a la responsabilidad patrimonial por las reparaciones que se realizan con base en los daños producidos en los conflictos armados; por ejemplo, punitiva, preventiva, control social, económica, solidaria, reparadora, transformadora y reparación integral. El acuerdo de paz colombiano ha incorporado los lineamientos

\footnotetext{
${ }^{24}$ Ver Acuerdo Final, 24 de noviembre de 2016, p. 181-182, disponible en: <https://goo.gl/VRHqXX>.

${ }^{25}$ Ver Acuerdo Final, 24 de noviembre de 2016, p. 182-183, disponible en: <https://goo.gl/VRHqXX>.

${ }^{26}$ Ver Acuerdo Final, 24 de noviembre de 2016, p. 184, disponible en: <https://goo.gl/VRHqXX>.

${ }^{27}$ Ver Acuerdo Final, 24 de noviembre de 2016, p. 184-186, disponible en: <https:/goo.gl/VRHqXX>.
} 
tendientes a la realización de la reparación integral, siguiendo los parámetros imperantes en la doctrina, la legislación y la jurisprudencia colombiana, aunque existen fuertes críticas.

El tema de las reparaciones integrales a las víctimas de los daños causados dentro del conflicto armado interno, está desarrollado principalmente en el quinto apartado del "Acuerdo final para la terminación del conflicto y la construcción de una paz estable y duradera” se titula "Sistema integral de Verdad, Justicia, Reparación y No Repetición”. El acuerdo siguiendo parámetros del derecho internacional y de la propia jurisprudencia colombiana, ha establecido medidas de reparación integral para la construcción de la paz, clasificándolas en individuales y colectivas.

Las medidas individuales de reparación integral son mecanismos encaminados a satisfacer a la víctima de una manera particular, se busca que el individuo sea resarcido totalmente en cada uno de los daños sufridos, bien sean sicológicos, físicos, económicos o a su dignidad. El acuerdo establece como medidas individuales de reparación integral para la construcción de la paz las de restituir, indemnizar, rehabilitar, satisfacer, no repetir y recuperación emocional. Desafortunadamente, no profundiza en cada una de las anteriores nociones; tampoco, hace referencia a los tipos de daños que reconocerá y no es clara sobre la actualización de los valores de las condenas.

Las reparaciones colectivas integrales buscan tutelar los derechos de varias víctimas que han sido sufrido daños similares, como consecuencia de unos hechos parecidos; también, se puede tratar de colectivos o grupos de personas que han sufrido de daños conjuntos. En todo caso, deben quedar completamente reparadas todas las lesiones padecidas, tanto los perjuicios materiales como los inmateriales. Las medidas colectivas de reparación contenidas en el Acuerdo son: actos tempranos de reconocimiento de responsabilidad colectiva, acciones concretas de contribución a la reparación, la reparación colectiva en el fin del conflicto, la rehabilitación psico-social, los procesos colectivos de retornos de personas en situación de desplazamiento y reparación de víctimas en el exterior, las medidas sobre restitución de tierras y la adecuación y fortalecimiento participativo de la Política de atención y reparación integral a víctimas en el marco del fin del conflicto y contribución a la reparación material de las víctimas.

Las medidas de reparación individual y colectiva, no son excluyentes entre sí; sin embargo, primero, se debe recurrir a las individuales y solamente, si no se logra una reparación total es conveniente acudir a las segundas. Esto garantiza que todos los daños sean efectivamente solventados, puesto que las reparaciones colectivas en ocasiones no llegan a todas las víctimas o se pueden destinar recursos a otros beneficios que no produzcan el resultado esperado.

Finalmente, el objetivo de la reparación integral patrimonial de los daños es que se indemnice totalmente a la víctima, para esto es necesario reconocer tanto los daños materiales como 
los inmateriales y que se actualicen los montos a los precios actuales. Se puede utilizar cualquier mecanismo individual o colectivo, lo importante es que no se indemnice dos veces por el mismo concepto.

\section{REFERENCIAS}

\section{BIBLIOGRÁFICAS}

ARENAS, Hugo. El régimen de responsabilidad objetivo. Legis, Bogotá, 2013.

ARENAS, Hugo. Un siglo de jurisprudencia del Consejo de Estado en materia de responsabilidad extracontractual. Ibáñez, Bogotá, 2015.

BREWER-CARÍAS, Alán; SANTOFIMIO, Orlando. Control de convencionalidad y responsabilidad del Estado. Universidad Externado de Colombia, Bogotá, 2013.

COLEMAN, Jules. Riesgos y daños. Marcial Pons, Madrid, 2010.

DE AHUMADA, Francisco. La responsabilidad patrimonial de las Administraciones Públicas. Aranzadi, Pamplona, 2009.

DOMÉNECH, Gabirel. "El principio de responsabilidad patrimonial de los poderes públicos”. En: Los principios jurídicos del derecho administrativo. Editorial la Ley, Madrid, 2010, p. 664-697.

GALGANO, Francesco. I fatti illecitti. Casa Edirtice Dott. Antonio Millani, Padova, 2008.

GARCÍA DE ENTERRÍA, Eduardo; FERNÁNDEZ, Tomás. Curso de Derecho administrativo II. Editorial Civitas, Navarra, 2015.

GHERSI, Carlos. Teoría de la reparación de daños. Editorial Astrea, Buenos Aires, 2013.

GIL, Enrique. La constitucionalización del derecho de daños. Editorial Temis, Bogotá, 2014.

HENAO, Juan. “Estado Social y Derecho administrativo”. En: La constitucionalización del derecho administrativo. Universidad Externado de Colombia, Bogotá, 2014, p. 145-201.

HENAO, Juan. "Las formas de reparación en la responsabilidad del Estado: hacia su unificación sustancial en todas las acciones contra el Estado". En: La responsabilidad extracontractual del Estado. Universidad Externado, Bogotá, 2015, p. 32-117

HENAO, Juan. El daño. Análisis comparativo de la responsabilidad extracontractual del Estadoen el derecho colombiano y en el francés. Universidad Externado de Colombia, Bogotá, 2007.

KOTEICH, Milagros. La reparación del daño como mecanismo de tutela de la persona. Universidad Externado de Colombia, Bogotá, 2012. 
LIBERATI, Alessio. La responsabilità della pubblica ammninistrazione ed il risarcimento del danno. Cedam, Padova, 2009.

MEDINA, Luis. “La responsabilidad patrimonial de las Adminsitraciones Públicas”. En: Lecciones y materiales para el estudio del derecho administrativo. Iustel, Madrid, 2009.

MIR, Oriol. La responsabilidad de la Adminsitración: hacia un nuevo sistema. Civitas ediciones, Madrid, 2002.

PAPAYANNIS, Diego. Compernsión y justificación de la responsabilidad extracontractual. Marcial Pons, Madrid, 2014.

REBOLLO, Luis. Responsabilidad patrimonial de las entidades locales. Editorial Iustel, Madrid, 2005.

RODRÍGUEZ, Libardo. Derecho administrativo. General y colombiano. Temis, Bogotá, 2015.

SAAVEDRA, Ramiro. La responsabilidad extracontractual de la Administración Pública. Editorial Ibáñez, Bogotá, 2003.

SANTOFIMIO, Orlando. "La cláusula constitucional de la responsabilidad del Estado: estructura, régimen y el principio de convencionalidad como pilar de su construcción dogmática”. En: Estudios sobre el control de convencionalidad. Colección de Estudios Jurídicos, n. 109, Editorial Juridica Venezolana, Caracas, 2015, p. 167-426.

TAMAYO, Javier. Tratado de Responsabilidad Civil II. Legis, Bogotá, 2011.

UPRIMNY, Rodrigo; GUZMAN, Diana. "En la búsqueda de un concepto transformador y participativo para las repraraciones en contextos transicionales”. En: Revista colombiana de derecho intenacional, n. 17, Bogotá, 2010, p. 232-286.

\section{JURÍDICAS}

Leyes

Ley 1592 de 2012.

Ley 446 de 1998.

Ley 448 de 2011.

Ley 975 de 2005.

\section{Sentencias de la Corte Constitucional}
C-029/09.
C-1199/08.
C-228/02.
C-286/14.
C-370/06. 
C-575/06.

\section{Sentencias de Unificación del Consejo de Estado}

28 de agosto de 2014. Exp. 26251.

28 de agosto de 2014. Exp. 27709.

28 de agosto de 2014. Exp. 28804.

28 de agosto de 2014. Exp. 28832.

28 de agosto de 2014. Exp. 31170.

28 de agosto de 2014. Exp. 31172.

28 de agosto de 2014. Exp. 32988.

28 de agosto de 2014. Exp. 36149.

Hugo Andrés Arenas Mendoza

Profesor principal de carrera de derecho administrativo, Universidad del Rosario, Bogotá, Colombia.E-mail: hugo.arenas@urosario.edu.co 